\title{
Rehin Mitigates Chronic Kidney Injury by Decreasing the Release of Perforin and IFN-Y from Immune Cells Via Inhibiting the STING/TBK1/IRF3 Pathway Activation
}

Jingyu Wang ( $\nabla$ cqfl_wjy@163.com )

The First Hospital of China Medical University: The First Affiliated Hospital of China Medical University https://orcid.org/0000-0003-1453-9587

\section{Xin Huang}

Shengjing Hospital of China Medical University

\section{Yong Liao}

Maoming People's Hospital

\section{Xintian Cai}

Xinjiang Medical University

\section{Jing Xu}

Second Military Medical University First Hospital: Changhai Hospital

Junfeng Hao

Affiliated Hospital of Guangdong Medical University https://orcid.org/0000-0002-2467-7345

Chao Zhu

Second Military Medical University First Hospital: Changhai Hospital

\section{Research Article}

Keywords: Rhein, CKD, renal fibrosis, perforin, IFN-ץ, immune cells

Posted Date: January 3rd, 2022

DOI: https://doi.org/10.21203/rs.3.rs-1169737/v1

License: (9) This work is licensed under a Creative Commons Attribution 4.0 International License. Read Full License 


\section{Abstract}

Shenkang suppository (SKS), a Chinese medicinal preparation rich in various natural ingredients, has not been reported in any studies related to fibrosis. Our experiments validated the anti-fibrotic and antiinflammatory effects of Rhein (Rh), which is a major component of SKS, and explored its potential immune mechanisms. Tissue and serum specimens from chronic kidney disease (CKD) patients and normal subjects were collected in 30 cases each, and the expression differences of perforin and IFN- $\gamma$ were analyzed by ELISA. Further, the CKD mice model constructed with folic acid (FA) was used to validate these differences by WB and qRT-PCR to explore the potential nephroprotective mechanism of $\mathrm{Rh}$. Besides, in vitro experiments were conducted to identify the release sources of perforin and IFN-ץ. ELISA showed that perforin and IFN- $\gamma$ were upregulated in CKD patients, and this phenomenon was also corroborated in CKD mice. WB and qRT-PCR data showed that Rh reversed perforin and IFN- $\gamma$ upregulation, inflammatory factor recruitment, and extracellular matrix (ECM) protein upregulation. Results from in vitro experiments demonstrate that the upregulation of perforin and IFN-y originates from the stress response of $\mathrm{CD} 4^{+} \mathrm{T}$ lymphocytes (CD4 ${ }^{+}$cells), $\mathrm{CD} 8^{+} \mathrm{T}$ lymphocytes (CD8 ${ }^{+}$cells) and natural killer cells (NK cells), which can be suppressed by Rh. More importantly, the activated STING/TBK1/IRF3 pathway in CKD was also inhibited by Rh. Our data suggest that Rh possesses anti-fibrotic and nephroprotective effects, which mechanistically are associated with decreased release of perforin and IFN- $y$ from immune cells, which may be achieved by suppressing the STING/TBK1/IRF3 pathway.

\section{Introduction}

As a global public health issue, CKD poses a tremendous challenge to human welfare and health, and the prevalence of CKD among adults in China has reached 10.8\% [1]. The common pathological features of CKD include renal interstitial fibrosis (RIF), glomerulosclerosis, and mall vascular sclerosis, and the former has received particularly close attention in the field of CKD because inhibition of RIF is more conducive to parenchymal recovery. The pathological mechanisms of RIF are closely related to multifarious factors, such as inflammatory response, apoptosis, oxidative stress, and imbalance of growth factors and cytokines [2-3]. Therefore, treatment strategies for CKD often revolve around these targets, but effective therapies are still lacking.

Immune cells are widely diffused in the organism and participate in antigen presentation, immune response and regulation, and in the pathogenesis of several immune-related inflammatory diseases. The roles of immune cells in kidney diseases are particularly sophisticated and, in some cases, even contradictory [4-5]. NK cells were classified into CD56 bright NK cells and CD56 ${ }^{\text {dim }}$ NK cells upon the difference in expression of CD56, both of which can be switched under certain conditions [6]. NK cells are involved in the interstitial lesions of immune nephritis [7], and CD56 ${ }^{\text {bright }} \mathrm{NK}$ cells in the interstitium can exacerbate CKD by secreting IFN- $y$ through signal transduction to obtain pro-inflammatory effects [8-10]. The released IFN-y also mediates early injury and inhibits tissue remodeling and fibrotic processes [11]. Moreover, NK cells can release cytotoxic particles like perforins through extravasation and employ the 
caspase pathway to inspire apoptosis in target cells [12-13]. CD4 ${ }^{+}, \mathrm{CD} 8^{+}$can also release IFN- $\gamma$ and perforin [14] and closely correlate with cardiovascular adverse events in CKD patients [15]. Previous studies have focused more on the efficacy of immune cells in kidney transplantation to observe the effects of toxicity and injury. However, effective immune monitoring is still lacking. In this context, we conceived this study and explored the mechanism of immune cells rescue in chronic kidney injury and prevention of renal fibrosis.

The stimulator of interferon genes (STING) is an important protein that links upstream DNA sensors and downstream factors in the innate immune signaling pathway [16], and its activation can trigger IFN immunity [17-18]. The second messenger cyclic guanosine monophosphate-adenosine monophosphate (cGAMP) directly activates STING and its key synthase cyclic GMP-AMP synthase (cGAS), which subsequently recruits STING to TANK-binding kinase 1 (TBK1) and activates downstream signals, such as activation of IFN regulatory factor 3 (IRF3) which then promotes IFN gene expression [19-20]. Notably, it is unclear regarding the involvement of the STING/TBK1/IRF3 pathway in the progression of renal fibrosis.

SKS has been used in China for over ten years as a representative class of agents for the treatment of chronic renal failure. Its curative mechanisms include inflammation and antioxidation and also the reparation of cellular injuries [21-24]. SKS primarily comprises extracts of 4 herbs used in Chinese medicines, namely rhubarb (Rheum Officinale), salvia (Salvia miltiorrhiza), safflower (Carthamus tinctorius $\mathrm{L}$ ) and astragalus (Astragalus membranaceous). Research has not been conducted to analyze the single components of SKS and to screen the therapeutic benefits of the corresponding components. $\mathrm{Rh}$, one of the main active components of rhubarb, has been recently reported for the treatment of renal fibrosis by mechanisms involving traditional targets such as oxidative stress and apoptosis [22, 25]. Given that tissue damage caused by fibrosis and inflammation can recruit resident cells to crosstalk with immune cells [26]. Therefore, intervening in immune cells or affecting their release of cytotoxic substances is beneficial for restoring local homeostasis and resolving cellular damage mediated by immune factors. However, it is unknown whether the renoprotective effect of Rh involves immune mechanisms. Consequently, we purified Rh from SKS by high-performance liquid chromatography (HPLC) technique and explored possible emerging immunotherapeutic strategies. In our study, we demonstrated for the first time the modulatory effect of Rh on immune cells and investigated the immune mechanism by which it exerts its renoprotective effect. Our data demonstrate that previously neglected immunomodulation has great therapeutic potential in the treatment of CKD, which may provide new clinical insights.

\section{Materials And Methods}

\section{Materials and HPLC}

SKS (Lot number: 202104113) was prepared and purchased from Century Sheng Kang Co. Ltd. (Xian, China) and the standard compounds: Rh, Emodin, Chrysophanol were purchased from the National 
Institute for the Control of Pharmaceutical and Biological Products (Beijing, China). The HPLC method was as follows: Octadecylsilane bonded silica gel was used as filler; The mobile phase was methanol$0.1 \%$ phosphoric acid (85:15); The detection wavelength was $254 \mathrm{~nm}$. The number of theoretical plates should not be less than 2000 according to Rh peak. Preparation of reference solution: Dissolve accurately weighed $1 \mathrm{mg}$ Rh, $2 \mathrm{mg}$ Emodin and $2 \mathrm{mg}$ chrysophanol reference substance into a $100 \mathrm{ml}$ volumetric flask with methanol and dilute to the scale. Preparation of test solution: Dissolve ten tablets of SKS $(0.6 \mathrm{~g})$ with methanol to dilute to the scale. Determination method: Inject $5 \mu$ l of the control solution and $5 \mu$ l of the test solution respectively to the HPLC system (Agilent Technologies, Santa Clara, CA, USA). The contents of Emodin, Chrysophanol were $0.2 \mathrm{mg} / \mathrm{g}$ and $\mathrm{Rh} 0.7 \mathrm{mg} / \mathrm{g}$, respectively. All the data were analyzed by Chemstation software. The results of HPLC analysis and the molecular formula of Rh are shown in Fig. 1.

\section{Acquisition of clinical specimens}

Thirty patients with stage III CKD (fibrosis group) who were hospitalized and underwent renal biopsy at the Department of Nephrology, The First Hospital of China Medical University from January 2020 to December 2020 were included in the case group, including three males and three females with a median age of 64 years (range: 47-80 years). Another thirty normal cases of renal specimens from the patients with post-traumatic nephrectomy (the cases with primary kidney diseases were excluded) were selected as the normal control group (normal group), including four males and two females, with a median age of 54 years (range: 37-69 years). Clinical specimens were acquired and mounted in OCT compounds (Tissue-Tek, Torrance, CA, USA) and stored at $-80^{\circ} \mathrm{C}$ for subsequent analysis.

\section{Animal experimental design}

A total of $24 \mathrm{C} 57 \mathrm{BL} / 6$ male mice (age, eight weeks; weight, $22 \pm 2 \mathrm{~g}$ ) were purchased from the animal laboratory of China Medical University. All the mice were kept in a specific pathogen-free facility and placed under standard laboratory conditions. The light/dark cycle was 12 hours, the temperature was $22 \pm$ $2{ }^{\circ} \mathrm{C}$, and the relative humidity was $55 \%-60 \%$. After one week of acclimatization, the mice were divided into NC, FA and FA+Rh groups using the random number table method ( $n=8$ per group). CKD mice model induced by FA was established in the FA and FA+ Rh group on the first day. The FA group was modeled by a single intraperitoneal administration of $F A$ at a concentration of $100 \mathrm{mg} / \mathrm{kg}$, which was prepared with $0.9 \%$ sodium bicarbonate injection. While in the FA+Rh group, after the intraperitoneal administration of FA, we gave continuous gavage administration of Rh at a concentration of $120 \mathrm{mg} / \mathrm{kg}$ once daily for 14 days. NC and FA groups were given equal amounts of vehicles by the same means. After two weeks, all mice were sacrificed. The left kidney was frozen to isolate RNA or protein, and the right kidney was perfused with PBS and fixed in 10\% paraformaldehyde buffer for histological examination. The schematic diagram of the animal experiment is shown in Fig. 2.

\section{Cell culture protocol}

The NK92 cells (purchased from ATCC) were stimulated for $4-8$ days by using $1000 \mathrm{U} / \mathrm{mL}$ IL-2 in RPMI 1640(Invitrogen, USA, New York Grand Island) supplemented with 10\% fetal calf serum (FCS), penicillin $(100 \mathrm{U} / \mathrm{mL})$, streptomycin $(100 \mathrm{~g} / \mathrm{mL})$, glutamine $(2 \mathrm{mM})$, sodium pyruvate $(1 \mathrm{mM})$, HEPES $(10 \mathrm{mM})$, and 
2-ME (0.5 mM). The CD $4^{+}$and CD8 ${ }^{+}$cells (purchased from ATCC) were cultured with $1640+2 \mathrm{mM}$ glutamine, $1 \mathrm{mM}$ sodium pyruvate, $10 \% \mathrm{FBS}$, and $1000 \mathrm{U} / \mathrm{ml} \mathrm{IL}-2$.

\section{Biochemical assays}

The plasma was collected by tail clamping method with heparin tube to determine the serum creatinine ( $\mathrm{SCr}$ ) and blood urea nitrogen (BUN) of mice on the 14th day after modeling. The samples were analyzed by kits purchased from Nanjing Jiancheng Institute of Biological Engineering (C011-2-1, C013-2-1) according to the method described by the manufacturer.

\section{Renal histopathology}

Both kidney tissues from mice and humans were fixed in 10\% paraformaldehyde buffer for $24 \mathrm{~h}$, followed by gradient alcohol dehydration, paraffin embedding, and sectioning $(4 \mu \mathrm{m})$, according to manufacturer's instructions for Hematoxylin and eosin (H\&E) and Periodic acid Schiff (PAS) and Masson's Trichrome (Masson) staining. The corresponding kits were purchased from Beijing Solabao (G1120, G1340, G1281). Renal injury including tubular and glomerular deformation and tubular epithelial cell detachment and assessed by semi-quantitative analysis with the following criteria: 0 : no abnormality; 1 : impairment less than $10 \%$; 2: impairment less than $25 \%$; 3 : impairment less than $50 \%$; 4 : impairment less than $75 \%$; 5 : impairment greater than $75 \%$. Semi-quantitative analysis of fibrotic area was assessed by Masson staining, i.e., calculating the percentage of blue staining over the entire view.

\section{Immunohistochemistry (IHC)}

Paraffin sections with tissue thickness of 4um were sequentially dewaxed, hydrated, and subsequently placed in xylene and graded alcohol, followed by antigen repair, DAB staining, hematoxylin re-staining, and finally sealed. The immunohistochemistry kit was purchased from MXB Biotechnologies (KIT-9710, DAB-0031), and the dilution ratios of the primary antibody were as follows: a- SMA (1:200, Abcam, ab5694), COL IV (1:200, Abcam, ab182744). Sections were photographed under a 400x light microscope (Olympus, Japan). The integrated optical density (IOD) of a-SMA and COL $₫$ was measured using ImagePro Plus 6.0, and the mean density was calculated by IOD/area.

\section{Western blot (WB)}

Tissue proteins were extracted according to kit instructions (Sigma Aldrich, PE0230, USA), and protein concentrations were routinely quantified by using a BCA kit (Beyotime Biotechnology, P0010S). Each sample was assayed for 30 ug by $8 \%$ or $12 \%$ SDS-PAGE, followed by semi-dry transfer to PVDF membranes (Millipore, USA). After blocking with 5\% skim milk prepared in TBST for $1 \mathrm{~h}$ at room temperature, the membranes were incubated overnight at $4^{\circ}$ with pre-diluted primary antibodies. The dilution ratios of all antibodies were as follows: Perforin (1:500, Thermo, MA5-12469), a- SMA (1:500, Abcam, ab5694), COL IV (1:500, Abcam, ab182744), STING (1:500, CST, \#13647), IRF3 (1:500, CST, \#4302), p-IRF3 (1:500, CST, \#29047), TBK1 (1:500, CST, \#38066), p-TBK1 (1:500, CST, \#5483). After the 
membrane was washed and incubated in secondary antibody (1:1000, affinity, s0001) for 1 hour at room temperature. Finally, the greyscale values were analyzed using ImageJ software.

\section{Quantitative real-time PCR analysis (qRT-PCR)}

Total RNA was extracted from the kidney by Trizol and enzyme RNA Extraction Kit (Takara, RR820A, China). Plentiful (1ug) RNA was reverse-transcribed by reverse transcription Kit (Takara, RR047A, China). Quantitative real-time PCR was performed subsequently with gene-specific primers (Biotechnology) and a 7500 abi biological system machine. The absolute mRNA number was calculated by comparison with the threshold. Primers for the examined genes are given in Table 1.

Table 1. Sequences for the primer pairs used for gene amplification in this study.

\begin{tabular}{llc}
\hline Target gene & Forward primer $\left(5^{\circ}-3^{\prime}\right)$ & Reverse primer $\left(5^{\circ}-3^{\prime}\right)$ \\
\hline$\alpha$-SMA & AGGAGGAGGTTACCATGAATG & GGTGATGATGCCGTGTTCTAT \\
COL-IV & CTGGACCCAAAGGCTCTCCG & GCCGATGTCTCCACGACT \\
Perforin & TGCAAGCAGAAGCACAAGTT & AAGGCCAGACGGTCTCCACC \\
TNF- $\alpha$ & TTCTCATTCCTGCTTGTG & AACTTCTCATCCCTTTGG \\
IFN- $\gamma$ & ATATCTGGAGGAACTGGCAAA & GGTGTGATTCAATGACGCTTAT \\
IL-6 & CGGAGAGGAGACTTCACAGAG & TCATTTCCACGATTTCCCAGAGA \\
IL-8 & GGGAGTATGATTTGTTGGAT & \\
GAPDH & TGTGTCCGTCGTGGATCTGA & ATGCTCAACACTATACAGAAG \\
\hline
\end{tabular}

\section{Enzyme-linked immunosorbent assay (ELISA)}

The following is the ELISA Protocol used in the present study: 1. Add antibody coating $\rightarrow 4^{\circ} \mathrm{C}$ overnight, wash three times, throw dry. 2. Add the antigen to be detected $\rightarrow 37^{\circ} \mathrm{C}$ for 30 minutes, wash three times, and dry. 3. Add enzyme-labeled antibody $\rightarrow 37^{\circ} \mathrm{C}$ for 30 minutes, wash three times, and dry. 4. Add substrate solution $\rightarrow 37^{\circ} \mathrm{C}$ for 15 minutes, add termination solution. 5 . The OD value was measured by ELISA. The production of perforin (Thermo Fisher, \#BMS2306), IFN-ץ (Thermo Fisher, \#KHC4021) were measured.

\section{Statistical analysis}


All statistical analyses were performed using GraphPad Prism 7.0 (GraphPad Inc, La Jolla, CA, USA). For the measurement data, continuous variables were expressed as mean \pm standard deviation $(x \pm s)$. Nonnormally distributed data were described as median (range). Categorical data were expressed as percentages. Differences in categorical variables among groups were determined by the Chi-square test, with the Yates' correction or the Fisher exact probability test as appropriate. Differences in continuous variables were determined by analysis of variance (unpaired Student's t-test) or non-parametric tests, as appropriate. Multiple comparisons were performed with two-way analysis of variance followed by Student's t-test with post hoc Bonferroni's correction. Comparison between the time points was performed by one-way ANOVA followed by pairwise comparisons with P-value adjustment. For all tests, a P-value (two-tailed) of $<0.05$ was recognized as a statistically significant statement if the study did not report any data.

\section{Results}

\section{CKD patients exhibit features of renal fibrosis and perforin induction}

The pathological staining of the biopsy specimens is shown in Fig. 3A. Generally, In the normal group, the kidney microstructure was normal. No anomalies were observed. Epithelial cells were not dilated or deformed, and there was no interstitial inflammation. In the fibrosis group, the glomerular morphology was changed, with abnormalities such as tubular dilatation and deformation, epithelial cell detachment, marked interstitial edema, diffuse infiltration of inflammatory cells and excessive collagen deposition. This is consistent with the IHC results of a-SMA (Fig. 3A, D), indicating that these patients all have typical fibrotic pathology. In addition, we focused on the expression of perforin and IFN- $\gamma$ in both groups. As shown by ELISA (Fig. 3E, F), perforin secretion was significantly increased in the fibrosis group compared to the normal group. This suggests that there may be a link between renal fibrosis and perforin and IFN- $\gamma$ induction.

\section{Rh alleviates renal dysfunction and fibrosis in FA-induced CKD mice model}

Generally, in our experiments, FA successfully caused deterioration of renal function in mice, as evidenced by a significant increase in SCr and BUN (Fig. 4A, B). Whereas renal function was preserved after Rh treatment, suggesting that Rh plays a nephroprotective role. H\&E and PAS staining (Fig. 4C-E) showed dilated tubules and interstitium, atrophy of tubular epithelium, and increased inflammatory cell infiltration in the FA group. The FA+Rh group showed distinctly fewer histological abnormalities than the FA group but still had a small proportion of aberrant glomeruli and proximal tubular epithelial cell hyperplasia with microprotein tubular patterns visible in the tubular lumen and occasional inflammatory cell infiltration in the interstitium. Masson staining (Fig. 4C, E) showed that collagen fibers were most abundant in the FA group, while Rh mitigated this trend. Furthermore, WB (Fig. 5A-C), IHC (Fig. 5D-F) and qRT-PCR (Fig. 5G, H) 
data demonstrated that Rh attenuates the FA-mediated ECM deposition. To summarize, these data suggest that we successfully established the FA-induced CKD mice model and proved that Rh could preserve renal function was associated with reduced ECM deposition.

\section{Rh suppresses perforin induction in FA-induced CKD mice model}

As displayed in Fig. 6A, B, the WB results showed that perforin was expressed at a significantly higher level in the FA group than in the FA+Rh and NC groups. The qRT-PCR (Fig. 6C) results were consistent with the WB scenario. These results suggested that high expression of perforin also occurred in CKD mice as in fibrosis patients. Animal experiments revealed that Rh inhibited FA-mediated induction of perforin.

We also examined the mRNA expression levels of some inflammatory factors, as shown in Fig. 6D-G, the expression of IFN- $y$, TNF- $a$, IL- 6 and IL-8 was significantly upregulated in the FA group, indicating that FAinduced CKD mice were accompanied by inflammatory disorders, whereas Rh inhibits the upregulation of the aforementioned inflammatory factors. Our results suggest that Rh exerts renoprotective and antifibrotic effects on the renal by inhibiting the expression of IFN- $\gamma$ and other inflammatory factors, as well as perforin.

\section{$\mathrm{Rh}$ represses the release of perforin and IFN-y from $\mathrm{CD}^{+}$, CD8 ${ }^{+}$and NK cells}

IL-2 is secreted by $T$ lymphocytes and is responsible for stimulating the growth and differentiation of T cells, B cells, and NK cells [27]. Therefore, we performed in vitro experiments using IL-2 treatment of immune cells to determine the source of perforin and IFN- $\gamma$ release. As shown by qRT-PCR results in Fig. 7A-F, IL-2 enhanced perforin and IFN- $\gamma$ release from $\mathrm{CD}^{+}, \mathrm{CD} 8^{+}$and NK cells. But this trend was reversed by $\mathrm{Rh}$. These results demonstrated that the perforin and IFN- $\gamma$ were derived largely from the $\mathrm{CD} 4^{+}, \mathrm{CD} 8^{+}$and NK cells as a response to stress out.

Rh inhibits the immune cells-mediated release of perforin and IFN-y from immune cells via inhibiting the STING/TBK1/IRF3 pathway activation

Previous studies have shown that nonspecific agonists of STING can induce IFN- $\gamma$ release from NK cells [25, 28-29], which suggests that STING signaling is involved in the release of cellular particles by immune cells. Therefore, we observed the effects of Rh treatment on the STING/TBK1/IRF3 pathway in the mice model and compared the WB results, as presented in Fig. 8A-D. We found that STING, p-TBK1 and p-IRF3 proteins were most pronounced in the FA group, while Rh inhibited this trend, suggesting that $\mathrm{Rh}$ inhibits the release of perforin and IFN- $\gamma$ from immune cells perhaps by inhibiting the STING/TBK1/IRF3 immune pathway activation.

\section{Discussion}


Renal fibrosis is a complex and prolonged course characterized by infiltration of inflammatory cells and damage to the renal parenchyma and interstitium, gradually leading to the formation of scar tissue [30]. The aberrant tissue repair allows excessive accumulation of ECM, including collagen (types I, III, and IV), fibronectin, and proteoglycans. Meanwhile, activated fibroblasts are transformed into myofibroblasts, and a-SMA is induced to generate constriction tension [31]. It seems difficult to change the irreversible fate of fibrosis simply by inhibiting the ECM sedimentation.

In recent years, NK cells have attracted increasing attention in the field of fibrosis. In 2017, elevated IFN- $\gamma$ levels of CD $56^{\text {dim }}$ NK cells and CD56 bright $N K$ cells in specimens from patients with renal fibrosis were found for the first time to be associated with decreased renal function [8]. In response to cytokine stimulation, $\mathrm{CD} 6^{+}$cells carry cytotoxicity and proliferate in the renal tubule interstitial matrix, which in turn receives activation signals and exerts anti-inflammatory (IFN- $\gamma$ ) effects in CKD, which indicates that this is a pathogenic phenotype. In addition, the activated receptor CD335 and the differentiation marker CD117 were selectively co-expressed on CD56 bright NK cells, and this co-expression is thought to be a source of pro-inflammatory cytokines as well as an intermediate factor in the development of fibrosis and deterioration of renal function [9, 32-34]. Zhang et al. found that NK cells can directly damage renal tubular epithelial cells in vitro and that perforin is also involved in their cytotoxic acquisition and deeply involved in fibrosis during their evolution [35-36]. Similarly, the accumulation of NK cells in renal tubules leads to irreversible renal fibrosis [37-39]. This is consistent with our data suggesting a correlation between renal fibrosis and increased perforin and IFN-ץ.

It has been indicated that CGAMP and STING can activate NK cells [13, 40-41], and are correlated with $\mathrm{CD}^{+}$and $\mathrm{CD} 8^{+}$recruitment [42-43]. In our study, we found that STING/p-TBK1/p-IRF3 pathway protein expression was significantly higher in the FA group than in the NC and FA+ Rh groups, as was fibrotic pathology and ECM protein expression, which indicates that the fibrotic environment exerts an activating effect on STING and its downstream molecules and that this may be responsible for the recruitment of NK cells, $\mathrm{CD} 8^{+}$and $\mathrm{CD} 4^{+}$cells and the release of perforin and IFN-y. A groundbreaking study demonstrated that the STING signaling is involved in the progression of renal fibrosis, but they focused on the upstream CGAS of STING, while the downstream of STING failed to be explored [44]. Together with their findings, we can draw the conclusion that CKD is accompanied by STING signaling activation, but the exact level of activation may be related to the modeling method and CKD staging. Furthermore, STING activation was also observed in the patients with liver fibrosis and animal models, while liver fibrosis and inflammatory responses were alleviated after STING downregulation [45], which is consistent with our experimental data, indicating that there exists a trigger for STING signaling in the fibrotic environment, and the specific molecule remains to be further screened. Given the role of STING in regulating multiple inflammatory and immune responses, an increasing number of studies suggest that STING is a promising new target for the treatment of liver, lung, and cardiac fibrosis [46-48]. The experiment in vitro showed that knockdown of STING could reduce TGF- $\beta$-promoted ECM deposition, and conversely, STING can accelerate TGF- $\beta$-induced fibrosis. Our study revealed in greater depth the activation of STING and its downstream in renal fibrosis patients and animal models, which may be 
responsible for the release of perforin and IFN- $y$ by immune cells. Therefore, new therapeutic strategies for renal fibrosis and chronic kidney injury could revolve around the inhibition of immune signaling pathways, including STING and its upstream and downstream, which may be of greater therapeutic significance in immune-related nephritis, such as lupus nephritis.

Previous studies have shown that Rh can significantly inhibit the compensatory hypertrophy and hardening of the glomerulus and the inflammatory response during the renal fibrosis progress. Meanwhile, it can reduce the excretion of urine protein and effectively improve the permeability of the glomerular filtration membrane and attenuate the loss of nephron [49-50]. Our study also demonstrated the renoprotective effects of Rh. Further investigation of the regulatory mechanisms of how Rh inhibits the release of cellular granules and inflammatory factors from immune cells may better predict its renoprotective outcome, which would allow us to more effectively utilize immunomodulatory therapeutic strategies to prevent kidney injury. Further investigation of the regulatory network and potential functions of immune cells in RIF requires the development of specific therapeutic agents capable of acting on the STING/TBK1/IRF3 signaling pathway for patients with fibrotic kidney disease.

\section{Conclusion}

Our data suggest that Rh may suppress perforin and IFN- $\gamma$ released from misguided immune cells in a pronounced pro-inflammatory response through inhibiting the STING/TBK1/IRF3 pathway activation and thereby attenuate renal fibrosis to rescue renal function. More importantly, we discovered for the first time the activation of STING downstream molecules in CKD mice model, which may help provide new strategies for clinical treatment of CKD. Moreover, our study revealed a new mechanism by which SKS exerts its renal protective effect, which would facilitate a more precise dissection of its pharmacological effects.

\section{Declarations}

\section{Funding}

This work was supported by the following funds: 1. the National Natural Science Foundation of China (Grant No. 81470970); 2. Liaoning Provincial Natural Fund Guidance Plan (2019-ZD-0426); 3. Special Fund for geriatric medical service and capacity improvement project of Jin Qiu Hospital of Liaoning Province(Grant No. SJQYNKY202009).

\section{Conflicts of Interest}

The author reports no conflicts of interest in this work.

\section{Author information}

Xin Hunag and Jingyu Wang have contributed equally to this work. 


\section{Author Contributions}

Conceptualization, H.X. and J.W.; Methodology and Investigation, X.H., J.W., Y.L., and X.C.; Formal analysis and software, Y.L., X.C. and J.X.; data curation, X.C.; Writing-original draft preparation, X.H. and J.W.; Writing-review and editing, H.X. and J.W., J.H. and C.Z.; Funding acquisition, J.H. and C.Z. All authors have read and agreed to the published version of the manuscript.

\section{Data Availability}

All the data in this study are available upon request through the correspondence author.

\section{Ethical approval}

The study was conducted according to the guidelines of the Declaration of Helsinki, and approved by the ethics committee of the First Affiliated Hospital of China Medical University and implemented after approval (Ethical Lot Number: AF-SOP-07-1,1-01). Informed consent was obtained from all subjects involved in the study, and written informed consent was obtained from the patients to publish this paper. All animal research was conducted in accordance with the Guiding Opinions on the Treatment of Laboratory Animals issued and the Laboratory Animal Guideline for Ethical Review of Animal Welfare issued by the National Standard GB/T35892-2018 of the People's Republic of China, and all operations performed on mice have approved the China Medical University Standards for the Laboratory Animals Welfare and Ethical Review (Permit Number: CMU 20211201).

\section{References}

1. Saran R, Li Y, Robinson B, Ayanian J, Balkrishnan R, Bragg-Gresham J, Chen JT, Cope E, Gipson D, He K, Herman W, Heung M, Hirth RA, Jacobsen SS, Kalantar-Zadeh K, Kovesdy CP, Leichtman AB, Lu Y, Molnar MZ, Morgenstern H, Nallamothu B, O'Hare AM, Pisoni R, Plattner B, Port FK, Rao P, Rhee CM, Schaubel DE, Selewski DT, Shahinian V, Sim JJ, Song P, Streja E, Kurella Tamura M, Tentori F, Eggers PW, Agodoa LY, Abbott KC US Renal Data System 2014 Annual Data Report: Epidemiology of Kidney Disease in the United States.American journal of kidney diseases: the official journal of the National Kidney Foundation2015, 66 (1 Suppl 1), Svii, S1-305.

2. Liu Y (2006) Renal fibrosis: new insights into the pathogenesis and therapeutics. Kidney Int 69(2):213-217

3. Pan MM, Zhang MH, Ni HF, Chen JF, Xu M, Phillips AO, Liu BC (2013) Inhibition of TGF- $\beta 1 /$ Smad signal pathway is involved in the effect of Cordyceps sinensis against renal fibrosis in $5 / 6$ nephrectomy rats. Food and chemical toxicology: an international journal published for the British Industrial Biological Research Association 58:487-494

4. Kim SY, Jeong EJ, Steinert PM (2002) IFN-gamma induces transglutaminase 2 expression in rat small intestinal cells. Journal of interferon \& cytokine research: the official journal of the International Society for Interferon and Cytokine Research 22(6):677-682 
5. Shi FD, Ljunggren HG, La Cava A, Van Kaer L (2011) Organ-specific features of natural killer cells. Nat Rev Immunol 11(10):658-671

6. Caligiuri MA (2008) Human natural killer cells. Blood 112(3):461-469

7. Furuichi K, Wada T, Iwata Y, Sakai N, Yoshimoto K, Shimizu M, Kobayashi K, Takasawa K, Kida H, Takeda S, Matsushima K, Yokoyama H (2001) Upregulation of fractalkine in human crescentic glomerulonephritis. Nephron 87(4):314-320

8. Law BMP, Wilkinson R, Wang X, Kildey K, Lindner M, Rist MJ, Beagley K, Healy H, Kassianos AJ Interferon-gamma production by tubulointerstitial human CD56(bright) natural killer cells contributes to renal fibrosis and chronic kidney disease progression. Kidney internationa/2017, 92 (1),79-88

9. Mehrotra P, Collett JA, McKinney SD, Stevens J, Ivancic CM, Basile DP IL-17 mediates neutrophil infiltration and renal fibrosis following recovery from ischemia reperfusion: compensatory role of natural killer cells in athymic rats.American journal of physiology. Renal physiology2017, 312 (3),F385-f397

10. Cox SN, Sallustio F, Serino G, Loverre A, Pesce F, Gigante M, Zaza G, Stifanelli PF, Ancona N, Schena FP (2012) Activated innate immunity and the involvement of CX3CR1-fractalkine in promoting hematuria in patients with IgA nephropathy. Kidney Int 82(5):548-560

11. Jiang D, Liang J, Hodge J, Lu B, Zhu Z, Yu S, Fan J, Gao Y, Yin Z, Homer R, Gerard C, Noble PW Regulation of pulmonary fibrosis by chemokine receptor CXCR3. The Journal of clinical investigation2004, $114(2), 291-9$

12. Guia S, Fenis A, Vivier E, Narni-Mancinelli E Activating and inhibitory receptors expressed on innate lymphoid cells.Seminars in immunopathology2018, 40 (4),331-341

13. Souza-Fonseca-Guimaraes F, Parlato M, de Oliveira RB, Golenbock D, Fitzgerald K, Shalova IN, Biswas SK, Cavaillon JM, Adib-Conquy M (2013) Interferon-y and granulocyte/monocyte colonystimulating factor production by natural killer cells involves different signaling pathways and the adaptor stimulator of interferon genes (STING). J Biol Chem 288(15):10715-10721

14. Boyden AW, Brate AA, Karandikar NJ (2018) Early IFNY-Mediated and Late Perforin-Mediated Suppression of Pathogenic CD4 T Cell Responses Are Both Required for Inhibition of Demyelinating Disease by CNS-Specific Autoregulatory CD8 T Cells. Front Immunol 9:2336

15. Yadav AK, Kumar V, Jha V (2013) Heat shock proteins 60 and 70 specific pro-inflammatory and cytotoxic response of CD4+CD28null cells in chronic kidney disease. Mediat Inflamm 2013:384807

16. Ishikawa H, Barber GN (2008) STING is an endoplasmic reticulum adaptor that facilitates innate immune signalling. Nature 455(7213):674-678

17. Paludan SR, Bowie AG (2013) Immune sensing of DNA. Immunity 38(5):870-880

18. Wu J, Chen ZJ (2014) Innate immune sensing and signaling of cytosolic nucleic acids. Annu Rev Immunol 32:461-488

19. Woo SR, Fuertes MB, Corrales L, Spranger S, Furdyna MJ, Leung MY, Duggan R, Wang Y, Barber GN, Fitzgerald KA, Alegre ML, Gajewski TF (2014) STING-dependent cytosolic DNA sensing mediates innate immune recognition of immunogenic tumors. Immunity 41(5):830-842 
20. Sun L, Wu J, Du F, Chen X, Chen ZJ (2013) Cyclic GMP-AMP synthase is a cytosolic DNA sensor that activates the type I interferon pathway. Science (New York, N Y) 339(6121):786-791

21. Wu X, Guan Y, Yan J, Liu M, Yin Y, Duan J, Wei G, Hu T, Weng Y, Xi M, Wen A (2015) ShenKang injection suppresses kidney fibrosis and oxidative stress via transforming growth factor- $\beta / \mathrm{Smad} 3$ signalling pathway in vivo and in vitro. The Journal of pharmacy and pharmacology 67(8):10541065

22. Wu X, Liu M, Wei G, Guan Y, Duan J, Xi M, Wang J Renal protection of rhein against $5 / 6$ nephrectomied-induced chronic kidney disease: role of SIRT3-FOXO3a signalling pathway. The Journal of pharmacy and pharmacology2020, 72 (5),699-708

23. Jiang C, Shao Q, Jin B, Gong R, Zhang M, Xu B (2015) Tanshinone IIA Attenuates Renal Fibrosis after Acute Kidney Injury in a Mouse Model through Inhibition of Fibrocytes Recruitment. Biomed Res Int 2015:867140

24. Du N, Xu Z, Gao M, Liu P, Sun B, Cao X (2018) Combination of Ginsenoside Rg1 and Astragaloside IV reduces oxidative stress and inhibits TGF- $\beta 1 /$ Smads signaling cascade on renal fibrosis in rats with diabetic nephropathy. Drug Des Devel Ther 12:3517-3524

25. Temizoz B, Kuroda E, Ohata K, Jounai N, Ozasa K, Kobiyama K, Aoshi T, Ishii KJ (2015) TLR9 and STING agonists synergistically induce innate and adaptive type-II IFN. Eur J Immunol 45(4):11591169

26. Brandt S, Ballhause TM, Bernhardt A, Becker A, Salaru D, Le-Deffge HM, Fehr A, Fu Y, Philipsen L, Djudjaj S, Müller AJ, Kramann R, Ibrahim M, Geffers R, Siebel C, Isermann B, Heidel FH, Lindquist JA, Mertens PR (2020) Fibrosis and Immune Cell Infiltration Are Separate Events Regulated by CellSpecific Receptor Notch3 Expression. Journal of the American Society of Nephrology: JASN 31(11):2589-2608

27. Signore A, Picarelli A, Annovazzi A, Britton KE, Grossman AB, Bonanno E, Maras B, Barra D, Pozzilli P (2003) 123I-Interleukin-2: biochemical characterization and in vivo use for imaging autoimmune diseases. Nucl Med Commun 24(3):305-316

28. Li XD, Wu J, Gao D, Wang H, Sun L, Chen ZJ (2013) Pivotal roles of cGAS-cGAMP signaling in antiviral defense and immune adjuvant effects. Science (New York, N Y) 341(6152):1390-1394

29. Lu S, Concha-Benavente F, Shayan G, Srivastava RM, Gibson SP, Wang L, Gooding WE, Ferris RL (2018) STING activation enhances cetuximab-mediated NK cell activation and DC maturation and correlates with HPV(+) status in head and neck cancer. Oral Oncol 78:186-193

30. Zheng L, Zhang C, Li L, Hu C, Hu M, Sidikejiang N, Wang X, Lin M, Rong R Baicalin ameliorates renal fibrosis via inhibition of transforming growth factor $\beta 1$ production and downstream signal transduction.Mol Med Rep2017, 15 (4),1702-1712

31. Chen WC, Lin HH, Tang MJ Regulation of proximal tubular cell differentiation and proliferation in primary culture by matrix stiffness and ECM components.American journal of physiology. Renal physiology2014, 307 (6),F695-707 
32. Iwatani H, Nagasawa Y, Yamamoto R, lio K, Mizui M, Horii A, Kitahara T, Inohara H, Kumanogoh A, Imai E, Rakugi H, Isaka Y CD16+CD56+ cells are a potential culprit for hematuria in IgA nephropathy.Clinical and experimental nephrology2015, 19 (2),216-24

33. Law BM, Wilkinson R, Wang X, Kildey K, Lindner M, Beagley K, Healy H, Kassianos AJ Effector gammadelta T cells in human renal fibrosis and chronic kidney disease. Nephrology, dialysis, transplantation: official publication of the European Dialysis and Transplant Association - European Renal Association2019, 34 (1),40-48

34. Kurts C, Panzer U, Anders HJ, Rees AJ (2013) The immune system and kidney disease: basic concepts and clinical implications. Nat Rev Immunol 13(10):738-753

35. Zhang ZX, Wang S, Huang X, Min WP, Sun H, Liu W, Garcia B, Jevnikar AM (2008) NK cells induce apoptosis in tubular epithelial cells and contribute to renal ischemia-reperfusion injury. Journal of immunology (Baltimore, Md : 1950) 181(11):7489-7498

36. Wee YM, Go H, Choi MY, Jung HR, Cho YM, Kim YH, Han DJ, Shin S (2019) Tissue-resident natural killer cells exacerbate tubulointerstitial fibrosis by activating transglutaminase 2 and syndecan-4 in a model of aristolochic acid-induced nephropathy. BMB Rep 52(9):554-559

37. Fuhro MI, Dorneles GP, Andrade FP, Romao PRT, Peres A, Monteiro MB Acute exercise during hemodialysis prevents the decrease in natural killer cells in patients with chronic kidney disease: a pilot study. International urology and nephrology2018, 50 (3),527-534

38. Kim HJ, Lee JS, Kim JD, Cha HJ, Kim A, Lee SK, Lee SC, Kwon BS, Mittler RS, Cho HR, Kwon B (2012) Reverse signaling through the costimulatory ligand CD137L in epithelial cells is essential for natural killer cell-mediated acute tissue inflammation. Proc Natl Acad Sci USA 109(1):E13-22

39. Bjorkstrom NK, Ljunggren HG, Michaelsson J Emerging insights into natural killer cells in human peripheral tissues. Nature reviews. Immunology2016, 16 (5),310-20

40. Uchida T, Nakashima H, Ito S, Ishikiriyama T, Nakashima M, Seki S, Kumagai H, Oshima N Activated natural killer $\mathrm{T}$ cells in mice induce acute kidney injury with hematuria through possibly common mechanisms shared by human CD56(+) T cells.American journal of physiology. Renal physiology2018, $315(3), \mathrm{F} 618-\mathrm{f} 627$

41. Hägele H, Allam R, Pawar RD, Reichel CA, Krombach F, Anders HJ Double-stranded DNA activates glomerular endothelial cells and enhances albumin permeability via a toll-like receptor-independent cytosolic DNA recognition pathway. The American journal of pathology2009, 175 (5),1896-904

42. Pantelidou C, Sonzogni O, De Oliveria Taveira M, Mehta AK, Kothari A, Wang D, Visal T, Li MK, Pinto J, Castrillon JA, Cheney EM, Bouwman P, Jonkers J, Rottenberg S, Guerriero JL, Wulf GM, Shapiro GI PARP Inhibitor Efficacy Depends on CD8(+) T-cell Recruitment via Intratumoral STING Pathway Activation in BRCA-Deficient Models of Triple-Negative Breast Cancer.Cancer discovery2019, 9 (6),722-737

43. Parkes EE, Walker SM, Taggart LE, McCabe N, Knight LA, Wilkinson R, McCloskey KD, Buckley NE, Savage KI, Salto-Tellez M, McQuaid S, Harte MT, Mullan PB, Harkin DP, Kennedy RD Activation of 
STING-Dependent Innate Immune Signaling By S-Phase-Specific DNA Damage in Breast Cancer. Journal of the National Cancer Institute2017, 109 (1)

44. Chung KW, Dhillon P, Huang S, Sheng X, Shrestha R, Qiu C, Kaufman BA, Park J, Pei L, Baur J, Palmer $M$, Susztak K Mitochondrial Damage and Activation of the STING Pathway Lead to Renal Inflammation and Fibrosis.Cell metabolism2019, 30 (4),784-799.e5

45. Luo X, Li H, Ma L, Zhou J, Guo X, Woo SL, Pei Y, Knight LR, Deveau M, Chen Y, Qian X, Xiao X, Li Q, Chen X, Huo Y, McDaniel K, Francis H, Glaser S, Meng F, Alpini G, Wu C (2018) Expression of STING Is Increased in Liver Tissues From Patients With NAFLD and Promotes Macrophage-Mediated Hepatic Inflammation and Fibrosis in Mice.Gastroenterology155(6), 1971-1984.e4.

46. Wang X, Rao H, Zhao J, Wee A, Li X, Fei R, Huang R, Wu C, Liu F, Wei L (2020) STING expression in monocyte-derived macrophages is associated with the progression of liver inflammation and fibrosis in patients with nonalcoholic fatty liver disease. Lab Invest 100(4):542-552

47. Bennion BG, Ingle H, Ai TL, Miner CA, Platt DJ, Smith AM, Baldridge MT, Miner JJ A Human Gain-ofFunction STING Mutation Causes Immunodeficiency and Gammaherpesvirus-Induced Pulmonary Fibrosis in Mice. Journal of virology2019, 93 (4)

48. Zhang Y, Chen W, Wang Y (2020) STING is an essential regulator of heart inflammation and fibrosis in mice with pathological cardiac hypertrophy via endoplasmic reticulum (ER) stress. Biomedicine \& pharmacotherapy $=$ Biomedecine \& pharmacotherapie 125:110022

49. Chen Y, Mu L, Xing L, Li S, Fu S (2019) Rhein alleviates renal interstitial fibrosis by inhibiting tubular cell apoptosis in rats. Biol Res 52(1):50

50. He D, Lee L, Yang J, Wang X Preventive effects and mechanisms of rhein on renal interstitial fibrosis in obstructive nephropathy.Biological \& pharmaceutical bulletin2011, 34 (8),1219-26

\section{Figures}

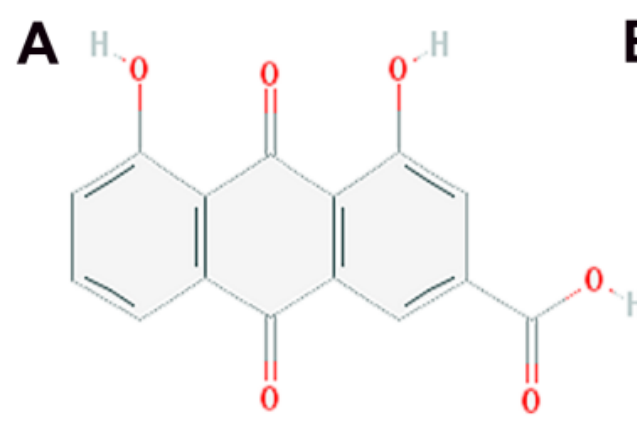

Rehin

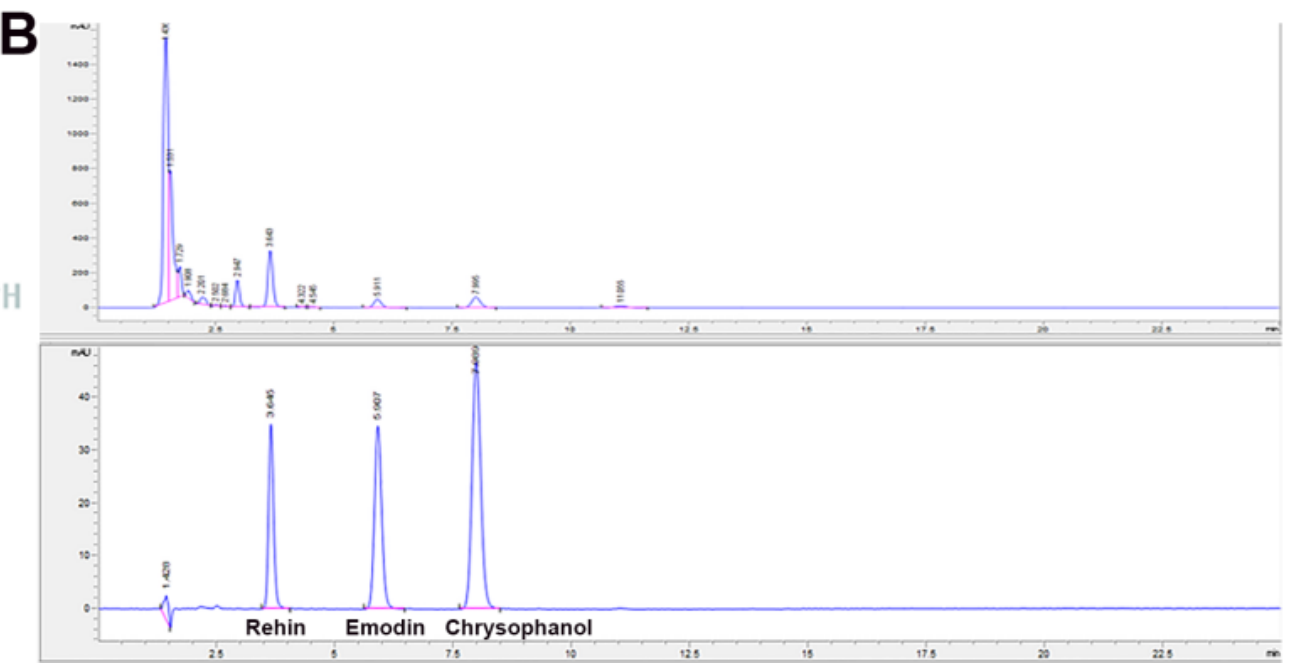

\section{Figure 1}


The molecular formula of Rh and the results of HPLC analysis.

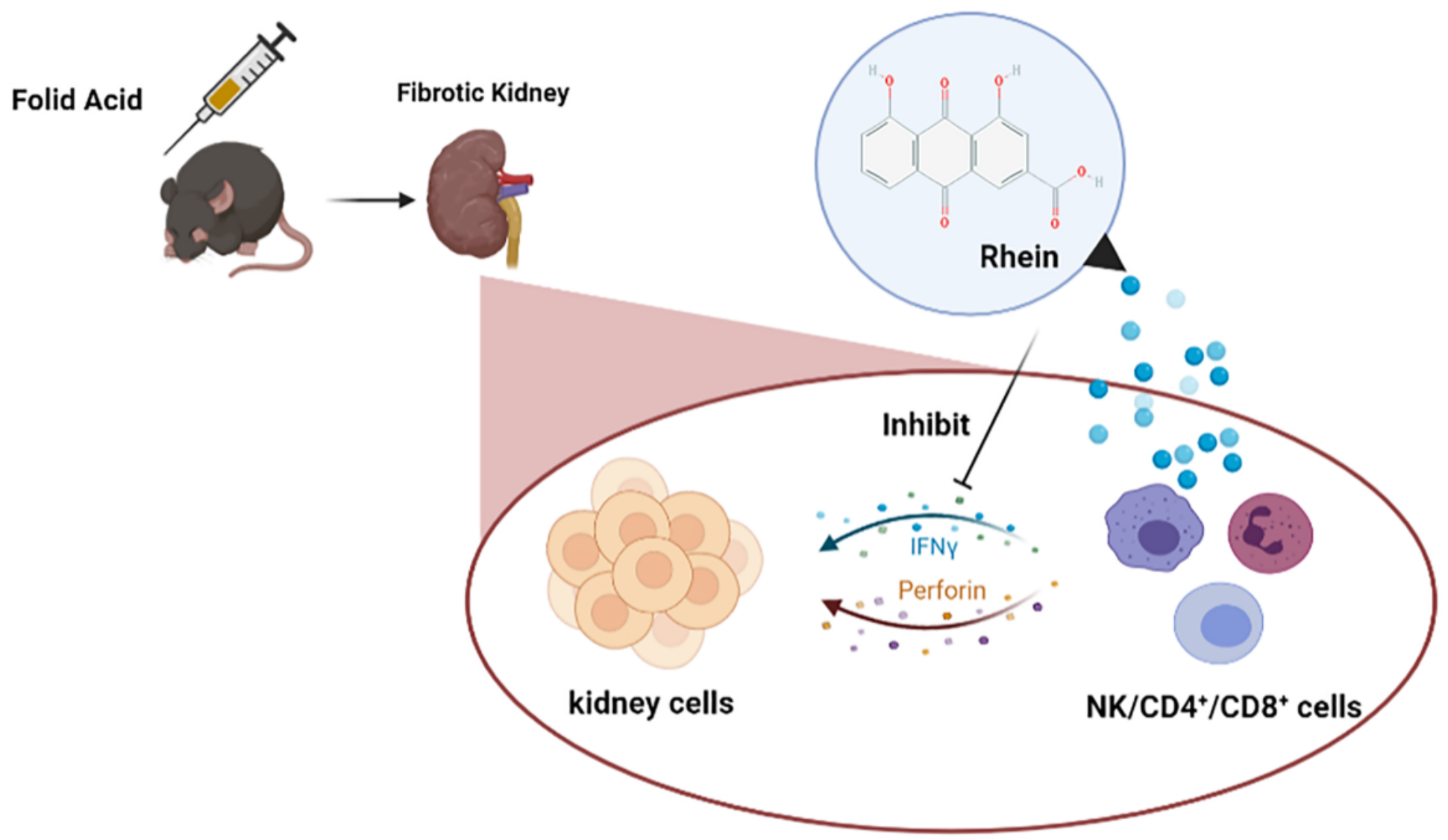

\section{Figure 2}

The schematic diagram of the animal experiment. 


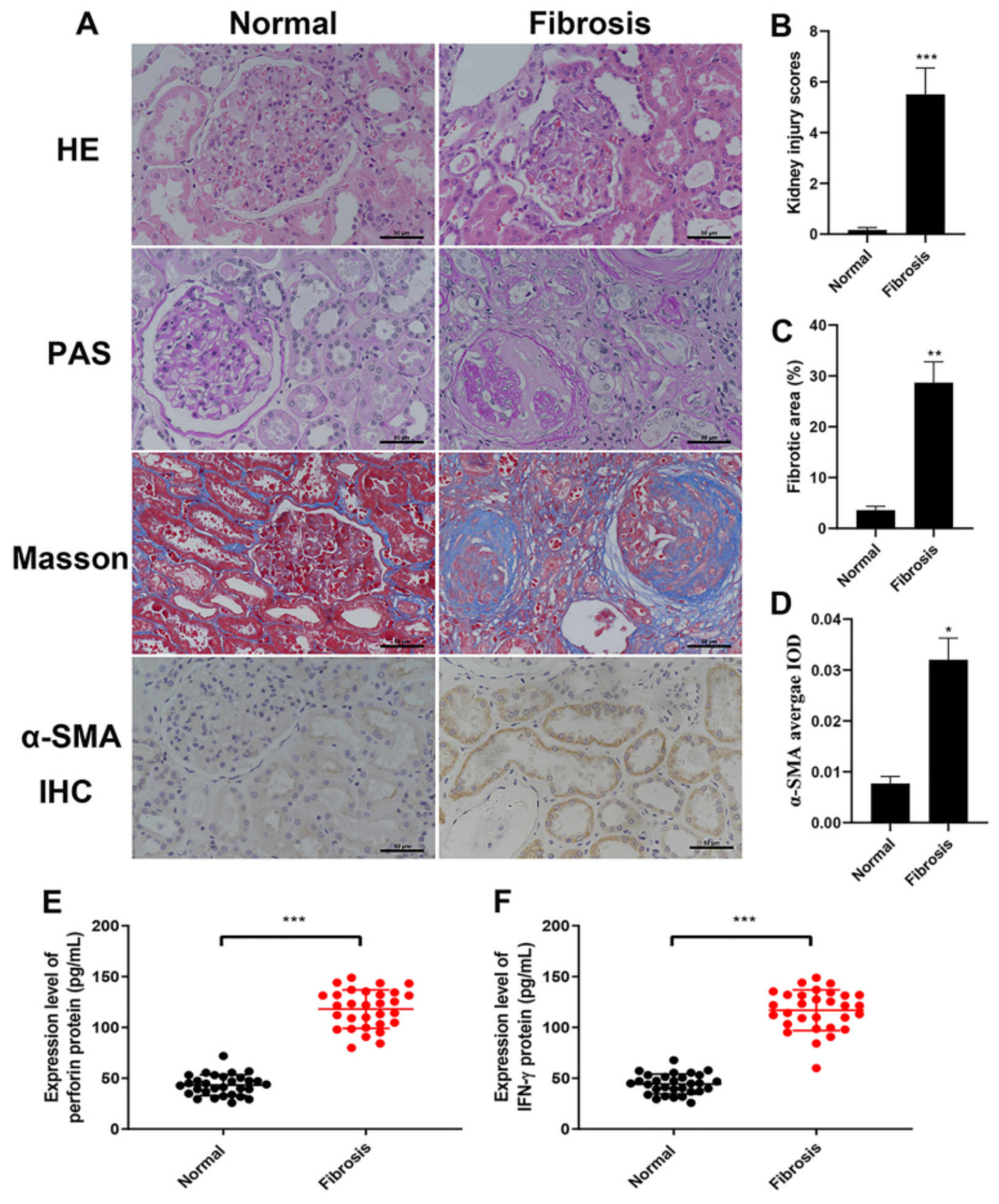

Figure 3

CKD patients exhibit features of renal fibrosis and perforin induction. (A) Representative pathological sections and IHC sections of the normal and fibrosis groups. (B) Kidney injury scores calculated from HE and PAS staining. (C) Fibrotic area calculated from Masson staining. (D) Results of semi-quantitative IHC analysis of a-SMA. (E, F) Perforin and IFN- $\gamma$ results of the two groups, measured by ELISA. ${ }^{*} * \mathrm{P}<0.001$, ${ }^{*} \mathrm{P}<0.01,{ }^{*} \mathrm{P}<0.05 \rrbracket v \mathrm{v}$ Normal group. Scale bar $=50 \mu \mathrm{m}$. 


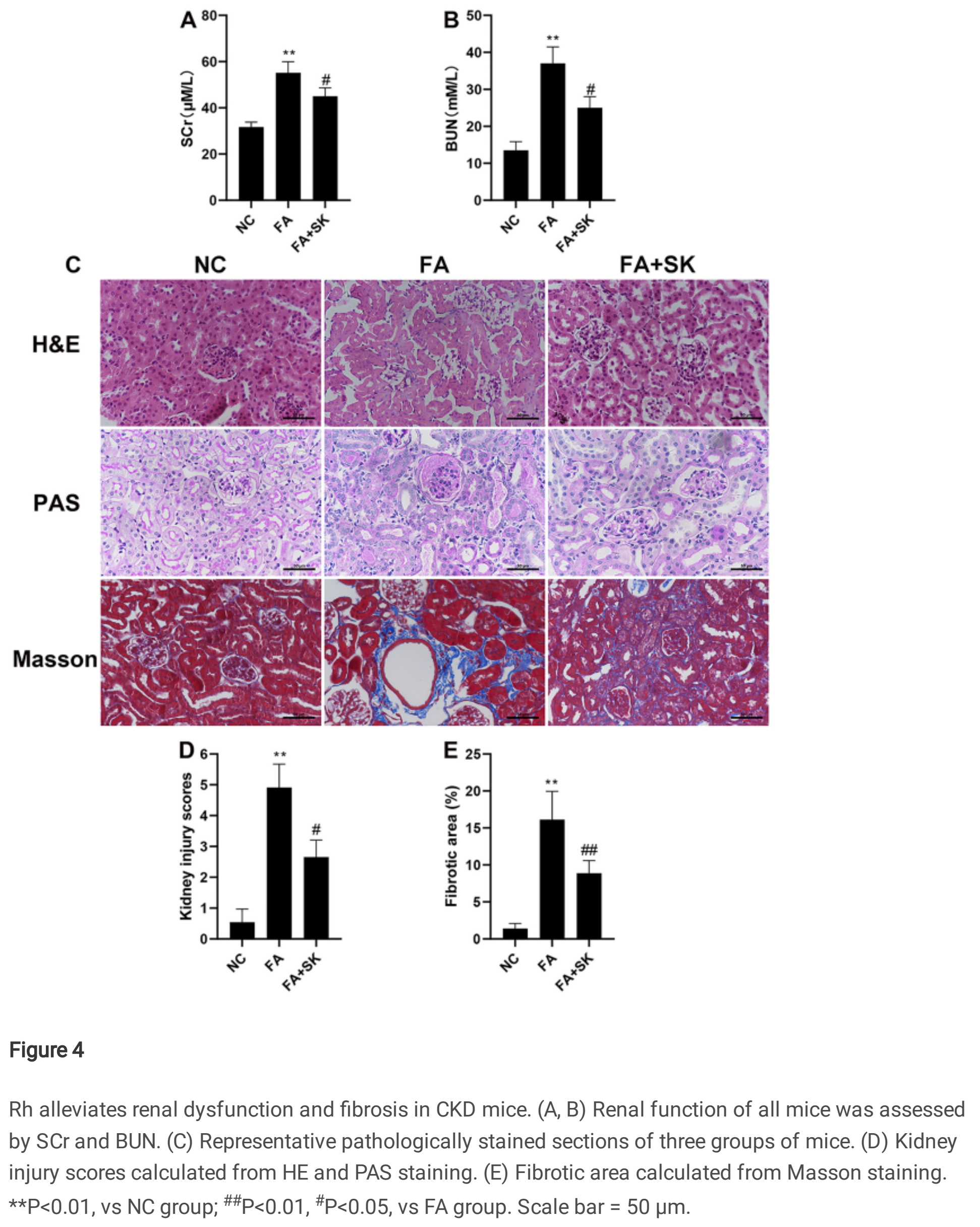



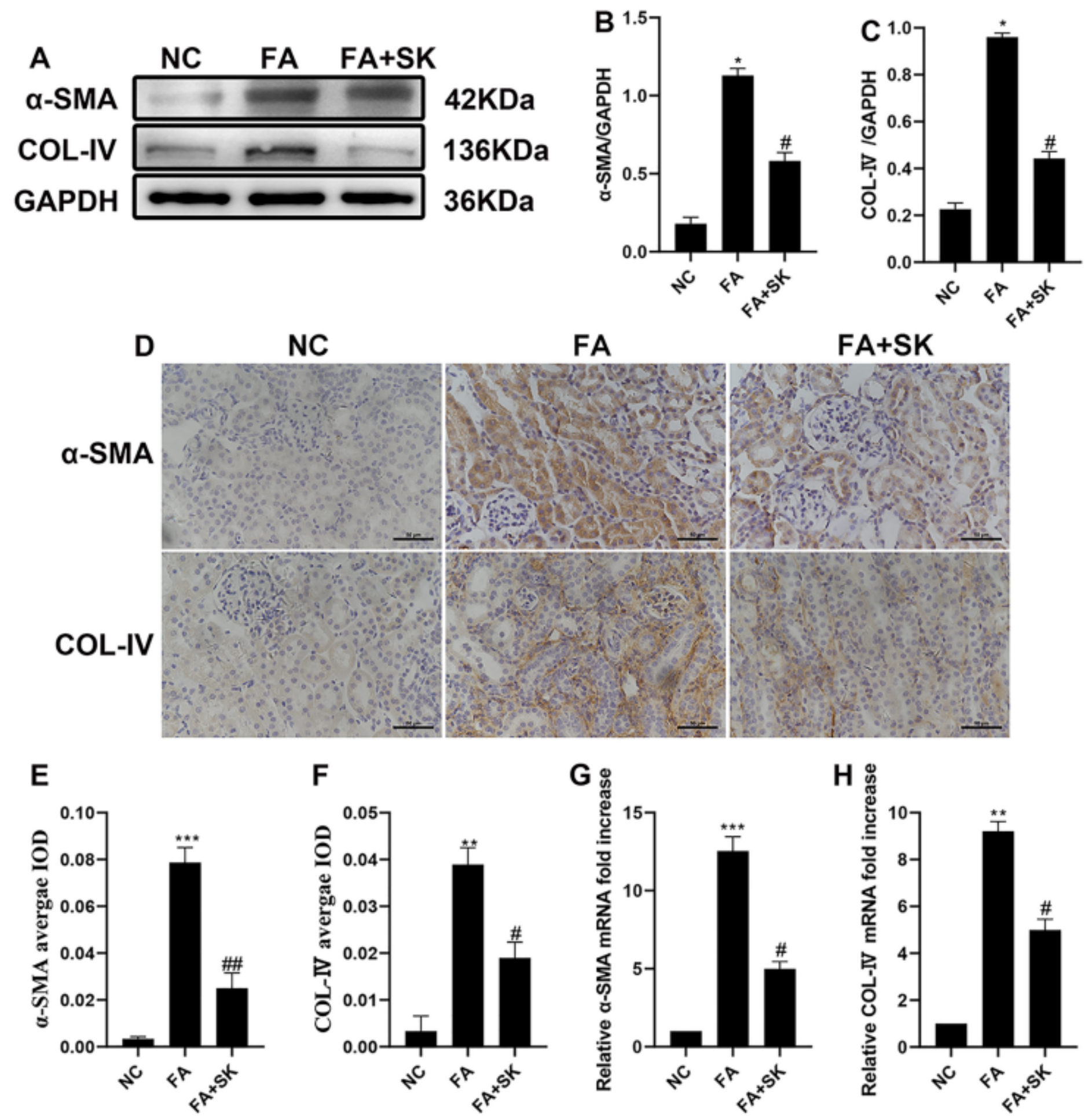

Figure 5

Rh alleviates ECM deposition in CKD mice. (A-C) The results of WB and semi-quantitative analysis of aSMA, COL IV. (D) Representative IHC sections of a-SMA and COL IV. (E, F) Results of semi-quantitative immunohistochemical analysis of a-SMA and COL IV. (G, H) a-SMA and COL IV was determined by qRTPCR and normalized to GAPDH. ${ }^{* \star *} \mathrm{P}<0.001,{ }^{* \star} \mathrm{P}<0.01,{ }^{\star} \mathrm{P}<0.05$, vs NC group; ${ }^{\# \#} \mathrm{P}<0.01,{ }^{\#} \mathrm{P}<0.05$, vs FA group. Scale bar $=50 \mu \mathrm{m}$. 


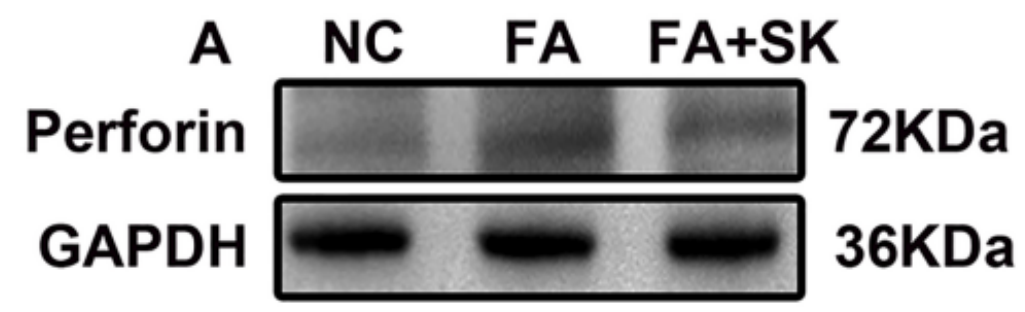

B
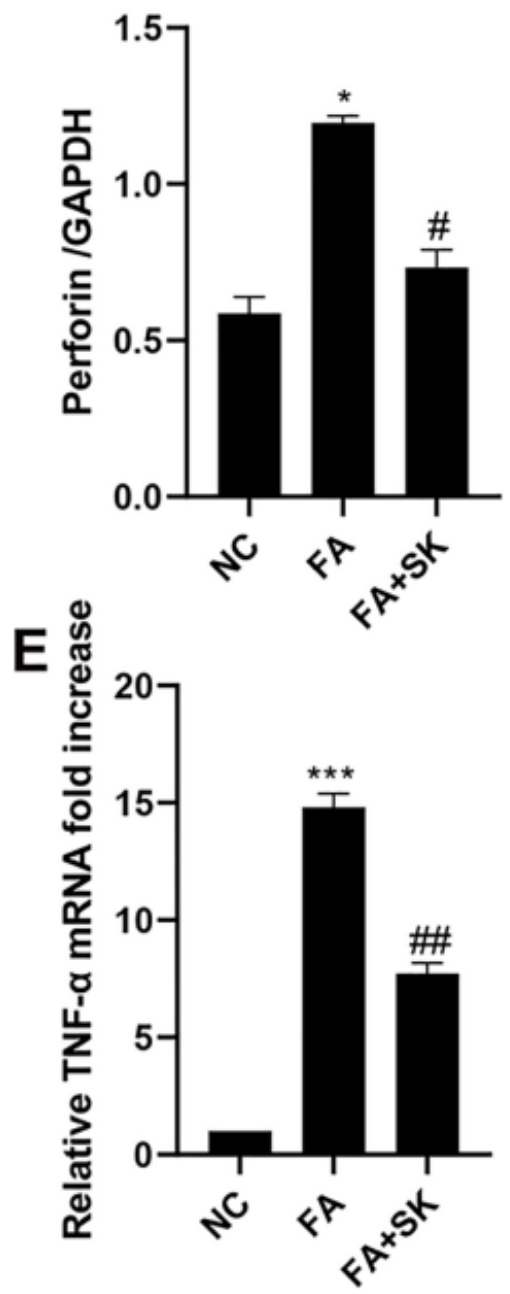

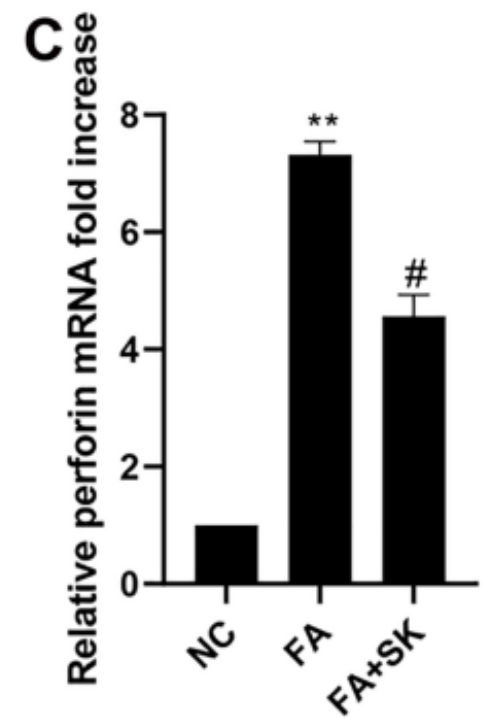

$F \check{\check{c}}$

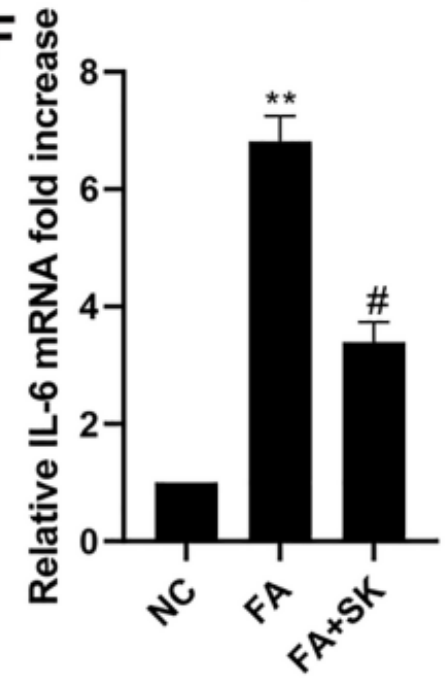

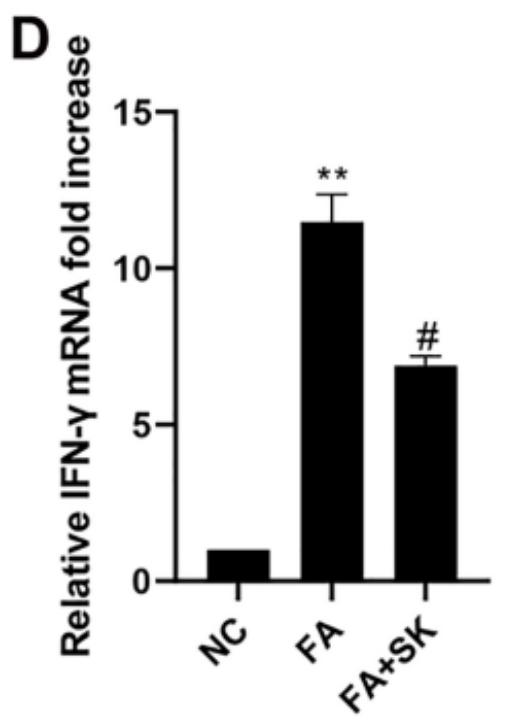

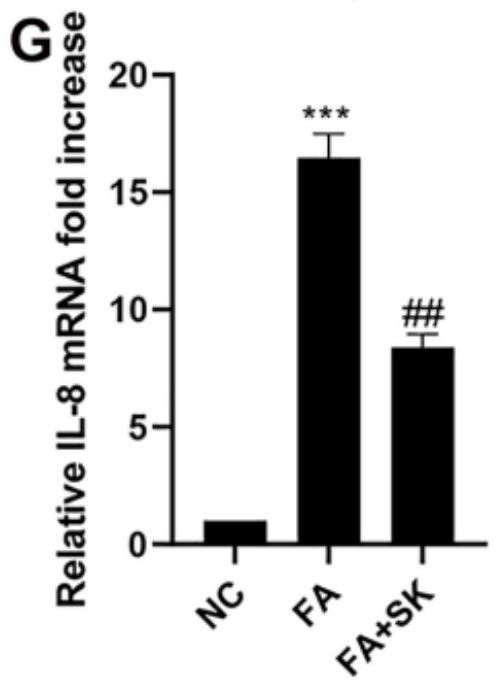

Figure 6

Rh suppresses perforin induction and inflammatory factor recruitment in CKD mice. (A, B) The results of WB and semi-quantitative analysis of perforin. (C-G) Perforin, IFN- $y$, TNF- $a$, IL- 6 and IL- 8 was determined by $q R T-P C R$ and normalized to GAPDH. ${ }^{* *} P<0.001,{ }^{* *} P<0.01,{ }^{*} P<0.05$, vs NC group; ${ }^{\# \#} P<0.01,{ }^{\#} P<0.05$, vs FA group. 

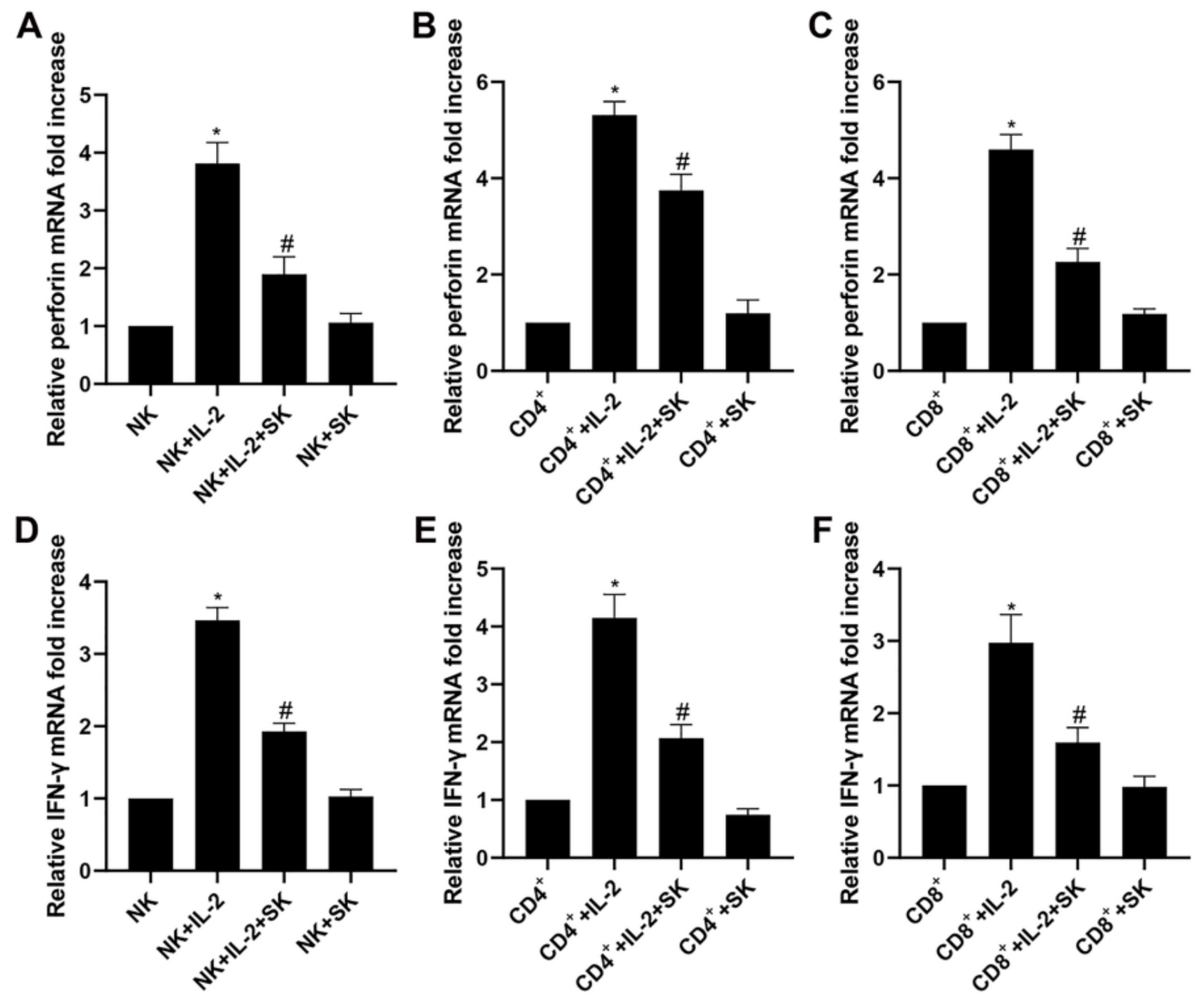

Figure 7

Rh represses the release of perforin and IFN- $\gamma$ from CD4 $4^{+}, \mathrm{CD}^{+}$and NK cells. (A-F) Perforin, IFN- $\gamma, \mathrm{TNF}-\mathrm{a}$, IL- 6 and IL- 8 was determined by qRT-PCR and normalized to GAPDH. ${ }^{*}<<0.05$, vs immune cell groups; ${ }^{\#} \mathrm{P}<0.05$, vs immune cell+IL-2 groups. 

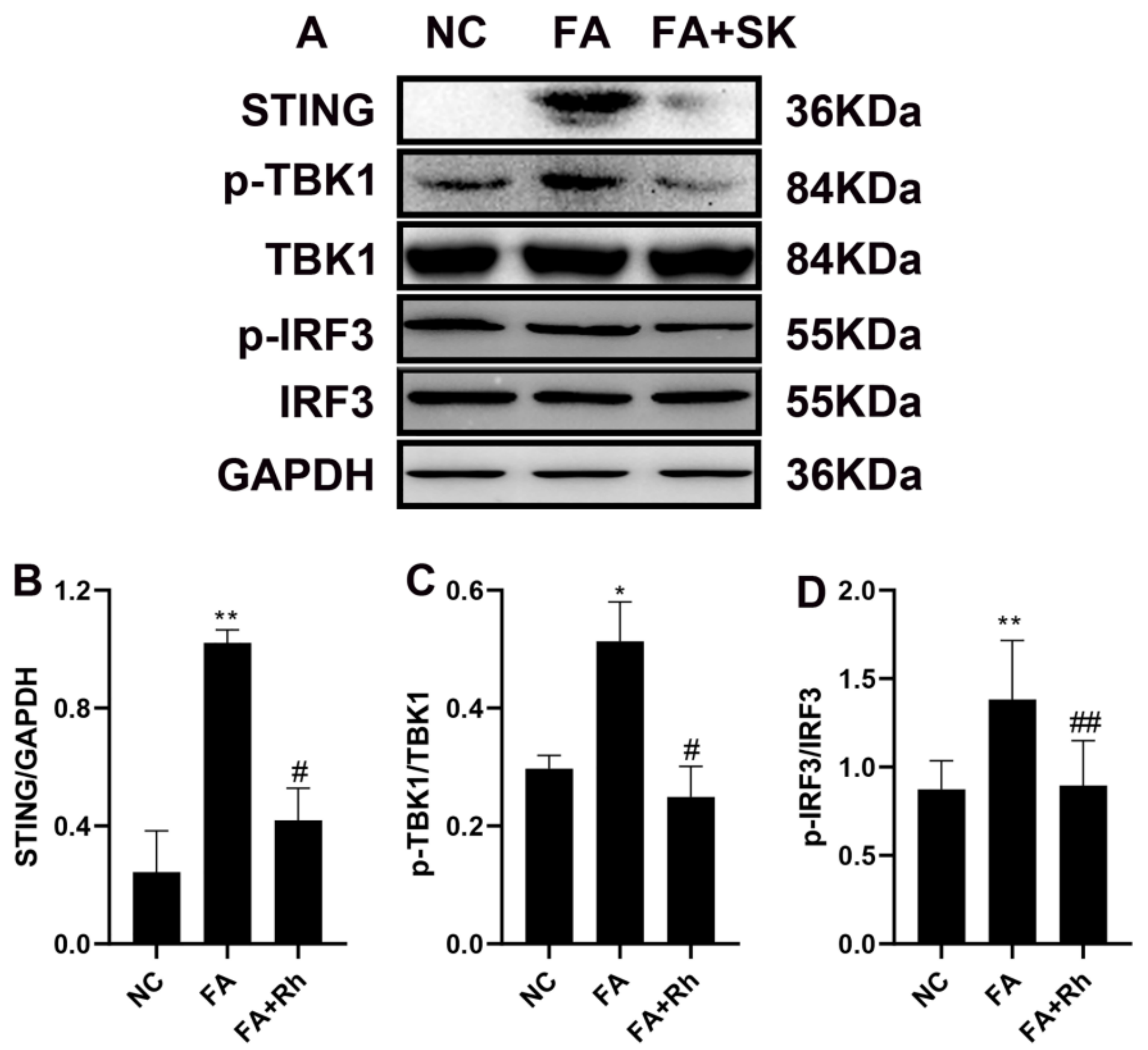

Figure 8

Rh inhibits STING/TBK1/IRF3 pathway activation. (A-D) The results of WB and semi-quantitative analysis of STING, $p$-TBK1, TBK1, p-IRF3 and IRF3. ${ }^{*} P<0.01,{ }^{*} P<0.05$, vs NC group; ${ }^{\# \#} \mathrm{P}<0.01,{ }^{\#} \mathrm{P}<0.05$, vs FA group. 